\title{
IgG4-related disease manifesting as pericarditis: A case report and Literature Review
}

\author{
Guillermo Quintero Vega ${ }^{1}$, Daniel Osorio ${ }^{2}$, Jose De la Hoz ${ }^{1}$, Karen Galvis ${ }^{1}$, Rafael \\ Andrade $^{1}$, and Daniela Rodriguez ${ }^{1}$ \\ ${ }^{1}$ Fundacion Santa Fe de Bogota \\ ${ }^{2}$ Universidad de los Andes
}

July 21, 2020

\begin{abstract}
IgG4-related disease (IgG4-RD) is a chronic inflammatory mediated by an immune response characterized by dense lymphoplasmacytic infiltrate, IgG4 positive plasmocytes in the affected tissue. In this case, we describe a patient who presented pericarditis with hemodynamic instability. Reporting of atypical presentations is necessary for broadening clinical recognition of similar cases.
\end{abstract}

\section{Hosted file}

Manuscript.doc available at https://authorea.com/users/344921/articles/471274-igg4-relateddisease-manifesting-as-pericarditis-a-case-report-and-literature-review
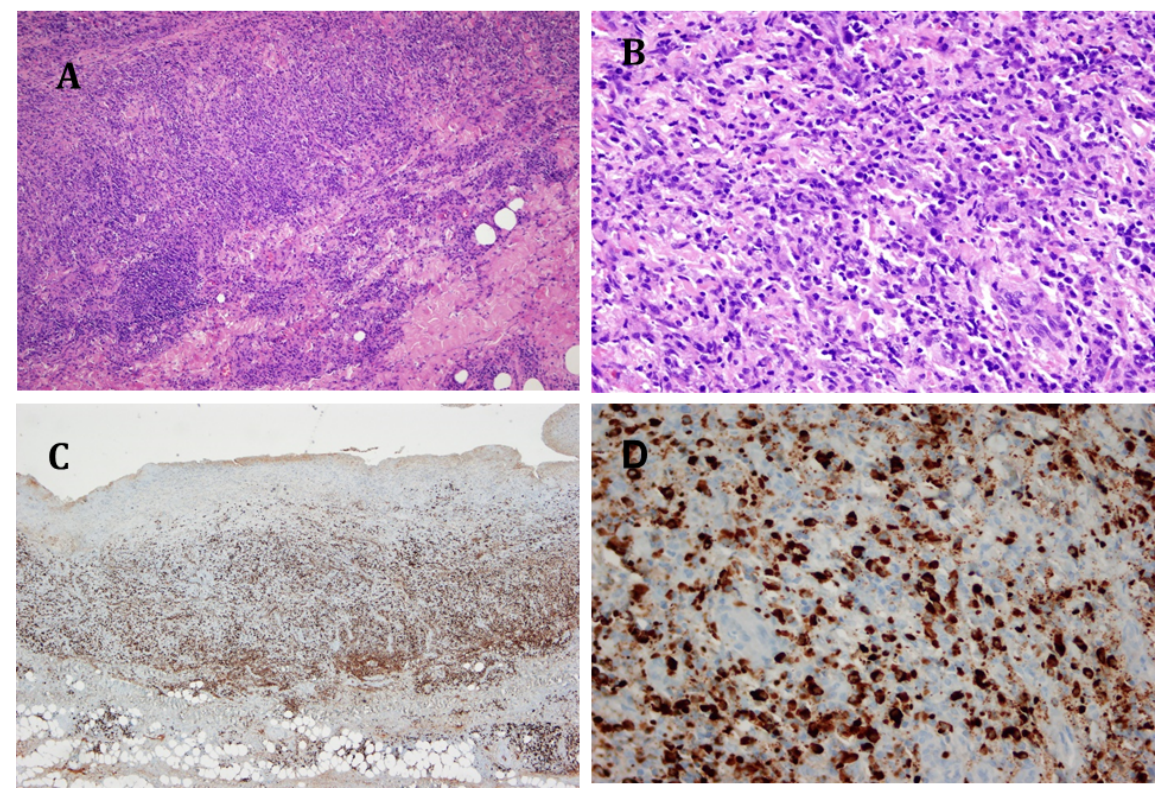

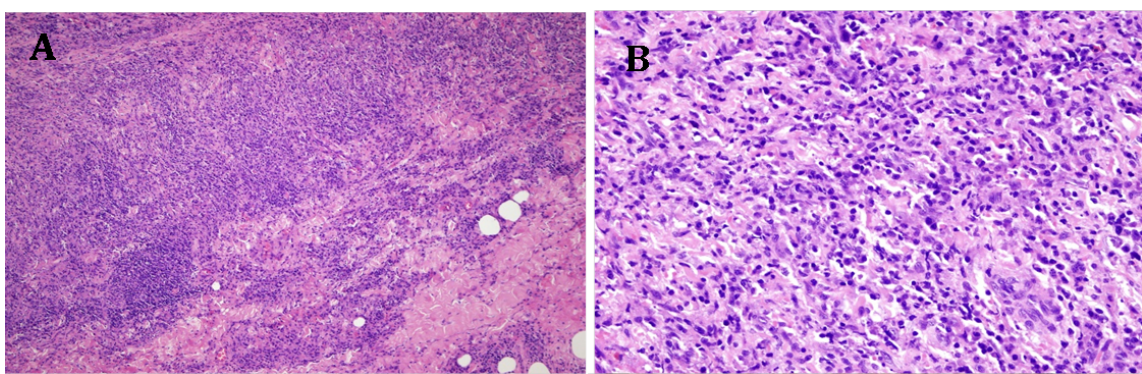

C
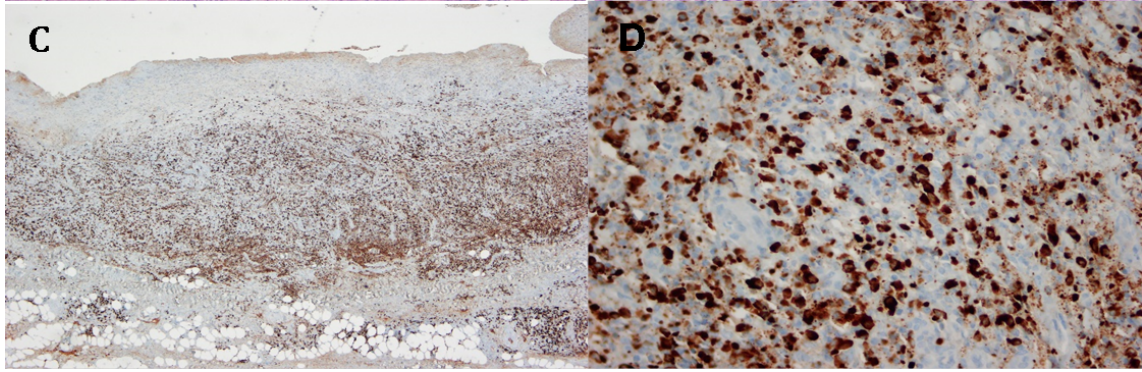